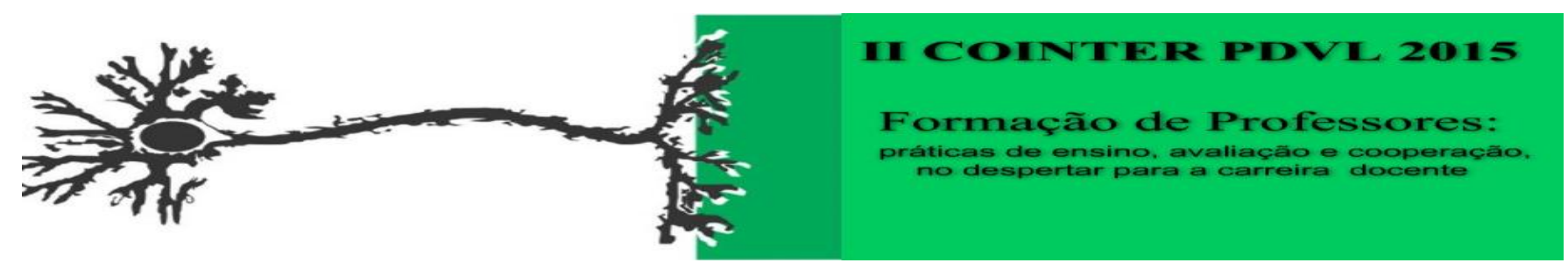

\title{
O ALVORECER DAS ATIVIDADES TÊXTEIS EM SÃO JOSÉ DO SERIDÓ - RN
}

Apresentação: Comunicação oral.

Hudson Alves da Silva.

Aluno do $6^{\circ}$ período do Curso Superior de Licenciatura Plena em Geografia Instituto Federal de Educação, Ciência e Tecnologia do Rio Grande do Norte (IFRN) - CNAT hudsonalves89@gmail.com

Cláudia Maria Salvador de Vasconcelos

Aluna do $6^{\circ}$ período do Curso Superior de Licenciatura Plena em Geografia Instituto Federal de Educação, Ciência e Tecnologia do Rio Grande do Norte (IFRN) - CNAT claudiavasconcelos3@ hotmail.com

Vandetânia Xavier Nascimento Aluna do $6^{\circ}$ período do Curso Superior de Licenciatura Plena em Geografia Instituto Federal de Educação, Ciência e Tecnologia do Rio Grande do Norte (IFRN) - CNAT taniaxn02@gmail.com

Maria Luiza de Medeiros Galvão Mestre em Geografia, Professora de Ensino Técnico Integrado e Superior Instituto Federal de Educação, Ciência e Tecnologia do Rio Grande do Norte (IFRN) - CNAT

luiza.galvao@ifrn.edu.br

\section{Resumo}

Este artigo apresenta os resultados do Projeto Integrador ${ }^{1}$, desenvolvido no $4^{\circ}$ período do Curso de Licenciatura Plena em Geografia do Instituto Federal de Educação, Ciência e Tecnologia do Rio Grande do Norte (IFRN), Campus Natal Central, alcançados em campo, por meio de visita a uma fábrica de bonés no município São José do Seridó no Rio Grande do Norte. Bonelarias e Facções ${ }^{2}$ associadas às atividades produtivas do setor têxtil estão em expansão na Região do Seridó Potiguar e São José do Seridó, objeto espacial desta pesquisa. Tais atividades vêm reorganizando a economia local, ao absorver sua população ativa nos setores citados e conectá-la aos circuitos da economia global. Essas mudanças são aqui entendidas como efeitos do processo de reestruturação produtiva, advinda do processo de globalização, o que evidencia racionalização dos custos de produção. $\mathrm{O}$ município de São José do Seridó está localizado na mesorregião Central do Estado e tem o quinto melhor índice de desenvolvimento humano municipal $(0,694)$. A metodologia segue breve revisão bibliográfica e entrevista semiestruturada, que possibilitou os resultados apresentados em forma de diálogo.

Palavras-Chave: Bonelaria. São José do Seridó. Reestruturação produtiva.

\footnotetext{
${ }^{1}$ Projeto Integrador: componente curricular das Licenciaturas do IFRN, propicia a integração entre os estudantes, os educadores e o objeto de conhecimento, sendo desenvolvido de maneira interdisciplinar.

2 Facções: empresas industriais terceirizados que prestam serviços exclusivos de costura e confecção para outras empresas de confecções, geralmente grandes indústrias.
} 


\section{Introdução}

A Região do Seridó do Rio Grande do Norte vem sendo incorporada ao fenômeno econômico de globalização em consequência da reestruturação produtiva do setor têxtil. As transformações socioeconômicas na região se iniciaram nas duas últimas décadas em um contexto de crises das economias tradicionais, com destaque para a atividade algodoeira, além da pecuária e da mineração (MORAIS, 2005a). O efeito do processo de reestruturação produtiva vem moldando a economia de pequenas cidades e considerando a reflexão de Morais (2005a, p. 01), um novo cenário compõe os municípios desta região desde o século $\mathrm{XX}$, a partir da reestruturação socioespacial e produtiva que redefiniu o padrão populacional, de preponderantemente rural a hegemonicamente urbano, e os caracteres da economia, de predominantemente agrários a prevalecentemente terciários.

No que se refere às bonelarias e facções no Seridó potiguar, o Pró-Sertão, programa executado em colaboração entre o Governo do Estado do Rio Grande do Norte, com a Federação das Indústrias do RN (FIERN) e o SEBRAE/RN teve participação, uma vez que seu objetivo era o desenvolvimento econômico interiorano com a implantação de facções de costura, aproveitando da ampliação do mercado do setor de confecções. O município de São José do Seridó (em destaque no mapa) foi contemplado diretamente pelas ações do Pró-Sertão e a presença da atividade faccionista têxtil e de bonelarias tem relevância local/regional. Dessa forma, o objetivo deste trabalho é apresentar o processo produtivo da bonelaria e sua influência na sociedade são-josé-seridoense, considerando as observações in loco, feitas durante visita de campo, a qual fez parte do projeto integrador.

Figura 01: Mapa de localização do município de São José do Seridó. Fonte: Própria.

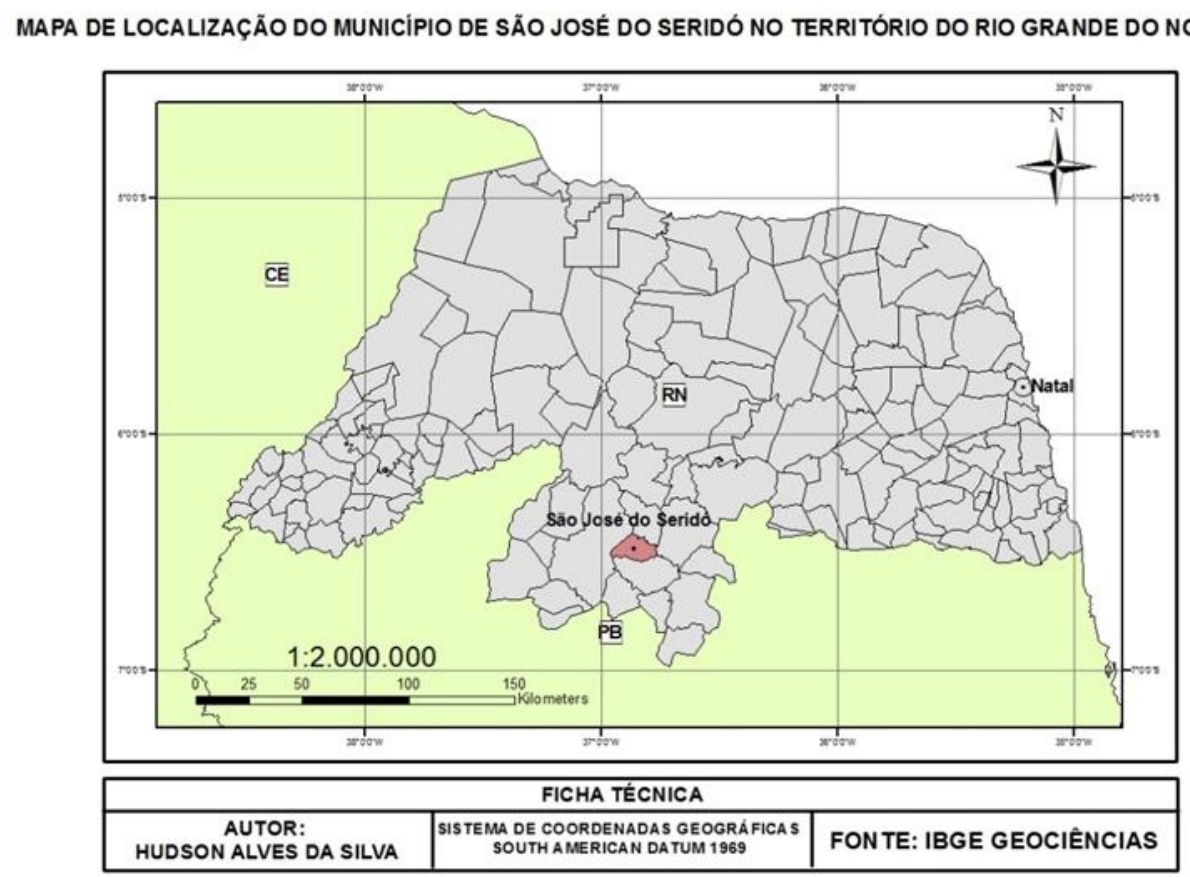


Para nossas reflexões recorremos às contribuições de Azevedo (2013), o qual aborda o processo de reestruturação produtiva no Rio Grande do Norte e Morais (2005a; 2005b), a qual escreve sobre a história do Seridó potiguar e o processo de reestruturação socioespacial em voga na mesma região. Assim, compreendemos que esse processo transforma significativamente os arranjos espaciais, quando dinamiza território ou ainda produz novos espaços. Nesse caminho foi possível identificar aspectos desses arranjos, a partir das observações realizadas na bonelaria em São José do Seridó e na cidade. Na bonelaria homens e mulheres se voltavam para as máquinas, enquanto a pequena cidade se apresentava silenciosa e vazia, conforme as figuras 02 e 03 .

Figura 02: Setor de produção da bonelaria. Fonte: Própria

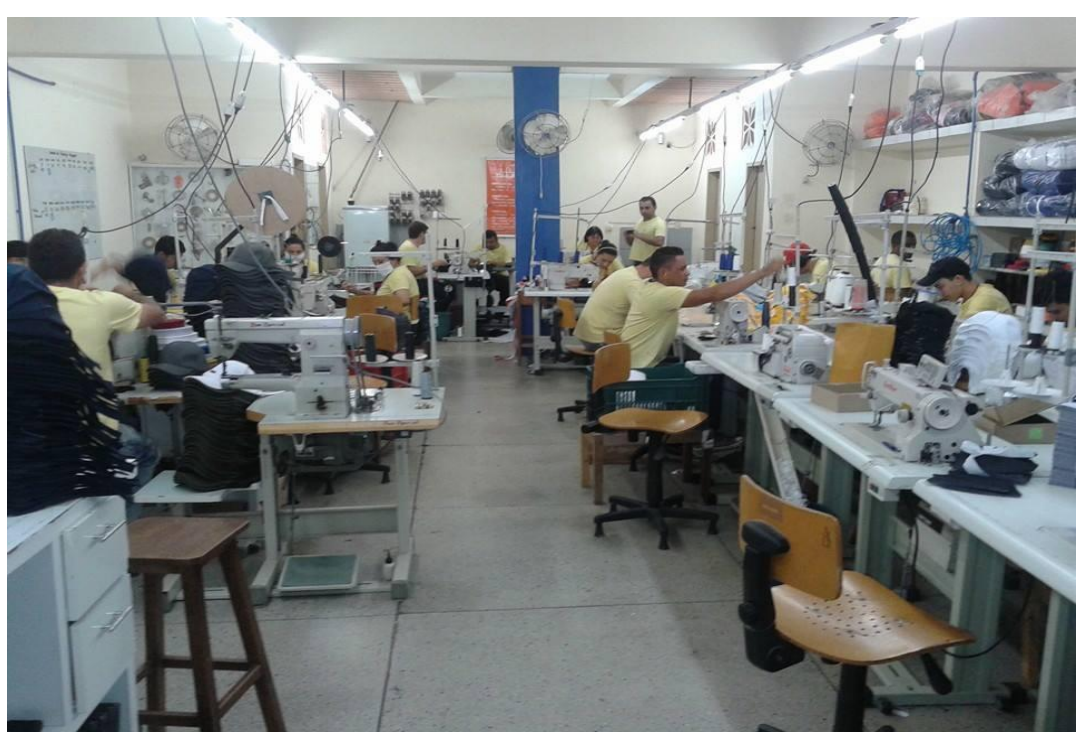

Figura 03: Aspecto urbano de São José do Seridó. Fonte: Própria.

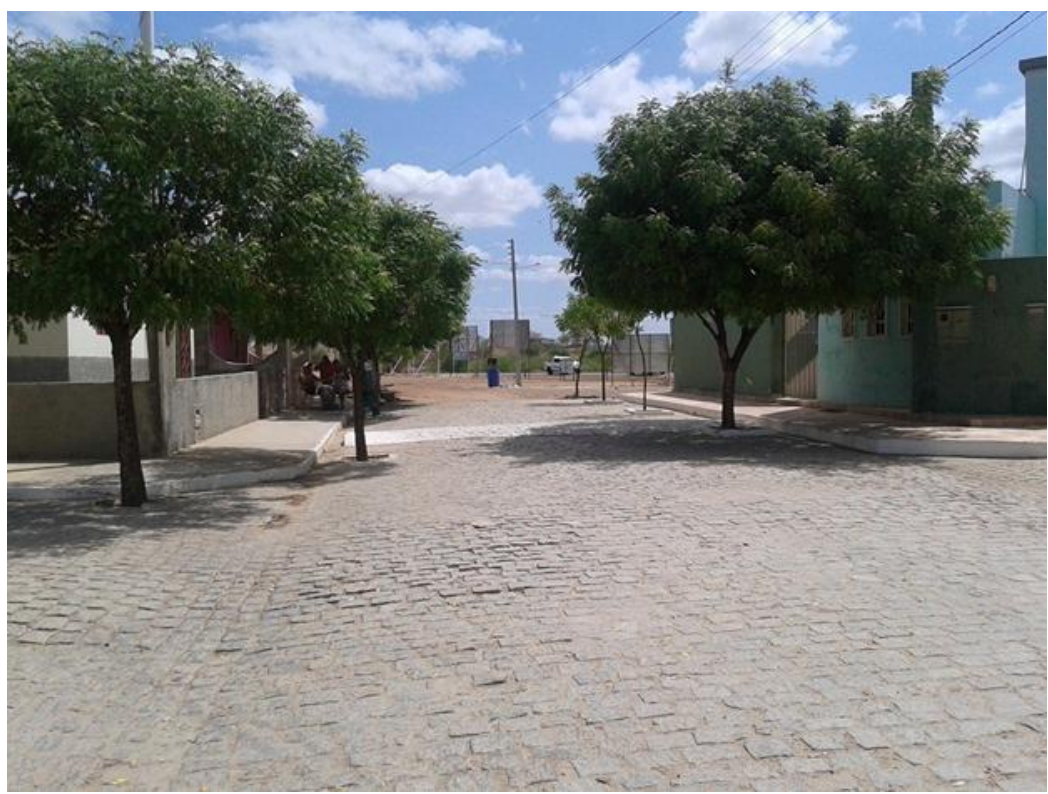


Por fim, o trabalho apresenta breve revisão bibliográfica a respeito do processo de reestruturação produtiva, o que propiciou relacioná-lo as atividades têxteis em São José do Seridó. Sobre o município tecemos considerações sobre sua caracterização geográfica e concluímos com os resultados das entrevistas realizadas.

\section{O diálogo entre o teórico e o empírico}

Considera-se a reestruturação produtiva como um movimento empreendido pelo grande capital monopolista na tentativa de criar novas estratégias de acumulação e reprodução em espaços que não proporcionam mais lucros, e, se proporcionam, não tanto quanto em dado momento histórico. Além disso, essa estratégia ocorre através do estabelecimento de novas atividades econômicas que emergem em territórios que tradicionalmente eram marcados por uma outra atividade econômica que perdeu espaço. A reestruturação produtiva é entendida por Azevedo (2013) como um processo marcado por transformações em várias dimensões do espaço geográfico econômica, política, técnica, social e ambiental, alterando substantivamente a divisão social e territorial do trabalho. Ainda conforme Azevedo (2013, p. 114),

\footnotetext{
O processo de reestruturação produtiva compreende um conjunto de transformações de caráter estrutural, organizacional e técnico, fazendo-se refletir no espaço geográfico em sua totalidade. Tais transformações se articulam e se configuram como alternativas de superação das crises cíclicas do sistema capitalista para a ampliação/reprodução do próprio capital, afetando sobretudo o mundo do trabalho, com contornos muito bem definidos, especialmente nos países subdesenvolvidos, onde o Estado do bem-estar-social ainda apresenta sérios problemas, limites e vulnerabilidades.
}

Nesse contexto, na primeira década do século XXI, no município de São José do Seridó, tal reestruturação se expressa através de duas vertentes bem delineadas: o estabelecimento das facções de costura, que são empreendimentos industriais de confecção e vestuário que prestam serviços exclusivamente para outras empresas de confecção, seja comércio ou indústria (MEDEIROS, 2005, apud SILVA, 2015), as quais possuem o objetivo de racionalizar seus custos e obter vantagens competitivas; e bonelarias, que são indústrias voltadas para a fabricação de bonés.

Por sua vez, o estabelecimento de novas empresas do ramo têxtil no município de São José do Seridó também pode ser considerado como um fator gerador de uma reestruturação socioespacial, também evidente, sobretudo, no Seridó Potiguar. Esta nova dinâmica socioespacial é compreendida no âmbito da reestruturação regional e torna-se evidente através da dinâmica populacional que engendra novas dinâmicas no território, como por exemplo, a urbanização de áreas onde a população vivia majoritariamente no campo. Santos (2007, p. 235), embasando-se nas 
considerações de Edward W. Soja, afirma que:

[...] compreendemos a reestruturação enquanto um processo resultante dos colapsos nas práticas sociais existentes, sendo impulsionadora de novas relações sociais e de novas lutas de classes surgidas no âmbito da sociedade. A reestruturação, nesse sentido, apresenta-se implicando fluxo e transição, fundamentando uma complexa e irresoluta mudança, emergida em face de crises.

Morais (2005a, p. 10), por seu turno, entende a urbanização ocorrida na Região do Seridó como "urbanização terciária", pois não houve uma transição da população do setor primário para o setor secundário e deste para o setor terciário. O estabelecimento de uma reestruturação na Região do Seridó Potiguar e por sua vez no município de São José do Seridó também é motivada pelo crescimento do setor terciário, especialmente porque este se dá antes do crescimento da atividade faccionista têxtil e das bonelarias locais.

\section{São José do Seridó/RN: Caracterização}

Inicialmente chamada de povoação da Bonita, em referência ao famoso poço do mesmo nome e situada à margem direita do rio São José, em um vale fértil, nasceu uma localidade com vocação para a criação de gado e a produção algodoeira, inserida na Região do Seridó. Nesse sentido, a atividade pecuarista foi fundamental para o processo de ocupação não só desta localidade, mas também para a Região do Seridó e a cotonicultura, que entra em evidência a partir da década de 80 do século XIX (MACÊDO, 2012), se constitui como uma das bases da economia local.

O novo núcleo teve como fundadores os senhores Justino Dantas, Antônio Alves da Costa, Miguel Berto do Melado, Pretinho do Trapiá e Francisco Pedro Dantas. Em consequência do desenvolvimento alcançado na pecuária e na cultura do algodão, a povoação, que passou a se chamar São José da Bonita, foi instalada oficialmente em 4 de novembro de 1917, com realização de uma feira livre realizada pelo presidente da Intendência de Jardim do Seridó, Dr. Heráclito Pires Fernandes. Através do Decreto ${ }^{\circ}$ 603, de 31 de outubro de 1938 o povoado foi elevado à categoria de distrito. Vinte e quatro anos depois, por força da Lei $n^{\circ} 2.793$, de 11 de maio de 1962, desmembrou-se de Jardim do Seridó e tornou-se município com o nome de São José do Seridó. A instalação do novo município aconteceu no dia 7 de abril de 1963 (IDEMA, 2008). Segundo Morais (2005b, p. 234),

A iniciativa de fundar um povoado no lugar surgiu das necessidades que os fazendeiros sentiam em relação a questões como sepultamentos e abastecimento de víveres para a sobrevivência diária, tendo em vista que as cidades próximas Caicó, Jardim do Seridó e Acari estavam relativamente distantes, em tempo de estradas e meios de transportes precários. Acrescentam-se, ainda, as dificuldades enfrentadas nos períodos chuvosos, 
quando os rios Seridó, São José e Acauã, que recortavam os caminhos de acesso às cidades mencionadas, transbordavam impedindo a circulação de pessoas e mercadorias.

O município de São José do Seridó localiza-se na mesorregião Central Potiguar e na microrregião Seridó Oriental. Limita-se ao norte com o município de Cruzeta, ao sul, Jardim do Seridó, a leste, Acari e a oeste Caicó. A sede do município dista da capital cerca de $248 \mathrm{~km}$, sendo seu acesso, a partir de Natal, efetuado através das rodovias pavimentadas BR-226, BR-427 e RN228 (BELTRÃO et al., 2005).

O município ainda possui uma população de 4.231 habitantes no ano de 2010 e para o ano de 2014 estimava-se uma população de 4.528 habitantes. A área do município corresponde a $174.505 \mathrm{~km}^{2}$ e a densidade demográfica é 24.25 hab./km² (IBGE, 2010). Além disso, em relação ao número de habitantes, o censo do IBGE (2010) constatou que vivem na cidade 2.122 homens, sendo que 494 residem na zona rural e 1.628 na área urbana. São 2.109 mulheres, sendo 435 na área rural e 1.674 na área urbana. Sendo assim, área urbana de São José do Seridó, residem 3.302 habitantes e na área rural 929.

O índice de desenvolvimento humano municipal, que leva em conta três aspectos longevidade, educação e renda - é 0,694 no ano de 2010, ainda conforme IBGE (2010). Este índice é o quinto maior do estado do Rio Grande do Norte, ficando atrás apenas de Parnamirim, Natal, Mossoró e Caicó. No ano de 2000 esse índice era de 0,588 e no ano de 1991 era de 0,435, o que revela um expressivo aumento deste indicador.

No ano de 2012 atuavam no município 103 empresas. O total de pessoas trabalhando com carteira assinada no município era de 769 e o de pessoas ocupadas total no município era de 882 . O salário médio mensal é de 1,3 salários mínimos. São José do Seridó possui um PIB a preços correntes de R \$ 36.947,00 e um PIB per capita de R \$ 8.592,22 (IBGE, 2012).

Historicamente, desde o estabelecimento do povoado que viria a dar origem ao município, em 4 de novembro de 1917, o grande destaque da economia local era a produção algodoeira e a pecuária. Aproximadamente em 1934 estabeleceu-se uma beneficiadora de algodão que fazia o processo de beneficiamento da matéria-prima, descaroçando e prensando o algodão que em seguida era transportado para Natal (MEDEIROS, 2014).

Entretanto, essa produção teve um significativo abalo no decêndio de 1970 e 1980 devido ao choque do petróleo em 1973, crise global com repercussões na Região do Seridó, à resistência à modernização das fábricas de beneficiamento, às frequentes secas do sertão, falta de controle fitossanitário, abertura do capital estrangeiro, o uso das fibras sintéticas, abertura das zonas econômicas exclusivas, dentre outros fatores.

Em 1990, no município de São Jose do Seridó, ressurgem as tecelagens. Em 1993 havia no 
município três tecelagens que produziam redes, cobertores, toalhas, etc. Objetivando qualificar a mão de obra capaz de operar as máquinas e gerenciar a produção, criou-se a "Escola Municipal de Aprendizagem Industrial Têxtil Raquel Eulália de Medeiros” (MEDEIROS, 2014).

Ainda no início da década de 1990, a primeira bonelaria foi instalada no município de São José do Seridó. Segundo Medeiros (2014), o boné foi um dos principais produtos da economia industrial de São José do Seridó e atraiu muitos jovens para as pequenas fábricas. Contudo, houve um enfraquecimento da indústria do boné e as facções se configuraram como motor da economia são-josé-seridoense, absorvendo grande número da mão de obra que era empregada na indústria do boné. Atualmente no município existem duas bonelarias, uma fábrica de peças íntimas, e quatorze facções dentro do projeto Pró-Sertão (FIERN, 2014).

Em entrevista concedida a revista da indústria do Rio Grande do Norte, número 7, editada pelo sistema FIERN no ano de 2014, o superintendente do IBGE-RN afirma que: "Hoje em são José do Seridó há pleno emprego. Esta é uma situação atípica no interior do estado, no sertão não acontece isso" (FIERN, 2014).

\section{Metodologia}

Os procedimentos metodológicos utilizados na composição desta pesquisa foram: breve pesquisa bibliográfica, a fim de dialogar com os autores que versam acerca do processo de reestruturação produtiva e socioespacial e suas relações com o município em tela e a Região do Seridó Potiguar; entrevista flexível e aberta, realizada com empreendedor local responsável pela bonelaria, a qual possibilitou o diálogo aberto entre entrevistador e entrevistado expressando maior conteúdo de informações; visita in loco, a fim de conhecer o processo produtivo da bonelaria, por meio da observação e entrevista semiestruturada sobre o trabalho realizado e a gestão da empresa.

As questões propostas versaram sobre produção, empregos, sazonalidade da produção e a importância das atividades desenvolvidas para o município. Para a entrevista recorremos ao contato direto no campo de estudo, a saber, a bonelaria em São José do Seridó. Assim, este trabalho consiste em pesquisa qualitativa.

A visita técnica feita à bonelaria foi parte do trabalho de campo realizado na Região do Seridó no dia 30 de janeiro de 2015 e atendeu a proposta de interdisciplinaridade para estudo do meio, com resultados apresentados em Seminário Integrador final realizado pelas disciplinas de Geografia Econômica e Climatologia, no âmbito das atividades previstas para o Projeto Integrador. 


\title{
Resultados e Discussão
}

No intuito de compreender a dinâmica econômica do setor da indústria têxtil no município de São José do Seridó, realizou-se uma entrevista com uma empresária do setor industrial, atuante no ramo de bonelaria. Inicialmente, a empresária apresentou o local de sua produção.

No setor de costura, onde a apresentação ocorreu, observa-se os colaboradores fardados, com equipamentos de proteção individual (calçado fechado, protetor auricular, etc.), num ambiente iluminado, climatizado e de fácil circulação.

A entrevista tem início com uma indagação sobre a quantidade de bonés produzidos:

\author{
(Empresária) \\ "Então aqui a gente produz [...] a gente tá com uma produção diária de 1500 peças, a nossa \\ estimativa, certo? É porque a gente tá em baixa."
}

A partir desta fala, percebe-se que a produção, especialmente de bonés, é afetada de acordo com as diferentes épocas do ano. Na empresa analisada, geralmente, a produção é bem maior nas proximidades das festas de fim de ano, carnaval ou em eventos que acontecem na região. No entanto, a produção não é interrompida, pois a bonelaria em foco já possui muitos clientes fixos, empresas de renome no cenário nacional e global. Sobre a atual produção, a empresária revela:

\footnotetext{
(Empresária)

"É baixíssima essa produção. A gente já teve que fazer até 4500 peças por dia."
}

Conforme nos relata a empresária, atuam em sua bonelaria 33 colaboradores diretos. A missão da empresa, anunciada em seu site oficial, é a seguinte: "Temos como missão produzir o melhor boné do Brasil”. A entrevista prosseguiu com perguntas que tentam desvendar melhor a dinâmica econômica do setor de indústria têxtil no município, tomando como referência a bonelaria:

\footnotetext{
(Entrevistador)

"A matéria-prima vem de onde?"

(Empresária)

"Caicó. Nós temos uma revenda lá. No lugar de nós termos um estoque, nós temos uma sociedade, temos quatro produtores e a gente tem uma loja em Caicó de onde a gente se abastece de lá. Tecidos e aviamentos em geral, salvo algumas matérias diferenciadas, porque a gente tem uma marca própria e nessa marca a gente traz insumos de Apucarana, Natal e Rondônia. Mas os demais a gente se abastece na região."

(Entrevistador)

"A produção daqui é exportada para quais cidades?"

(Empresária)

"Eu diria que quase todos os estados do país. Porque para quem a gente não tem uma venda direta, esporadicamente a gente vende [...] onde a gente menos vendia era no Rio Grande do Norte, agora a gente abriu um escritório lá em Natal."
} 
Os tecidos utilizados na confecção de bonés são guardados num pequeno quarto de outra casa próxima que é a extensão da bonelaria, onde se encontram as máquinas que fazem o corte a laser e o bordado.

Deu-se continuidade à entrevista, momento em que indagamos a empresária acerca de parcerias voltadas para a capacitação do empregado, que por ventura possam existir:

\footnotetext{
(Entrevistador)

"Vocês tem algum programa ou parceria que permita a melhor capacitação para os funcionários?"

(Empresária)

"Constantemente nós estamos reciclando, vem o IFRN e o SENAI. Nossa maior parceria é com o SENAI."
}

As micro e pequenas empresas do município de São José do Seridó contam com o incentivo do Pró-Sertão, programa presente em todo o Rio Grande do Norte que objetiva gerar 20 mil empregos diretos no interior do Estado, estimular a instalação de 360 pequenas unidades para produzir confecções (facções) e chegar à produção de 150 mil peças por dia. Trata-se de um programa que procura levar a industrialização ao interior do Rio Grande do Norte.

Neste programa, as instituições do sistema FIERN - SESI, SENAI E IEL - em parceria com o Governo do Estado atuam no sentido de qualificar empreendedores e trabalhadores que deverão trabalhar nas novas facções instaladas. O Pró-Sertão desenvolve suas ações desde 2013 e suas metas devem ser atingidas até o fim de 2018. Além disso, também objetiva capacitar as empresas fornecedoras por meio da melhoria da gestão empresarial e industrial e capacitar pessoas interessadas em qualificação profissional na área de vestuário.

A entrevista prosseguiu e foram levantadas algumas questões sobre os fatores que afetam a produção:

\begin{abstract}
(Empresária)
"A sazonalidade do nosso ramo complica [...] então nossos pedidos são sempre para ontem, porque quem trabalha pra eventos por mais que se programe termina isso aqui é pra tal dia [...] aquela correria, aquele desgaste. E a outra coisa é que hoje a gente tem uma nova realidade porque aqui antes aqui só existiam três fábricas, a nossa e mais duas [...] agora aqui a mão de obra está completamente envolvida em facções. Então eu acho que são aproximadamente 15 empresas. Hoje já não compensa mais abrir negócio aqui porque mão de obra já não existe. Existem várias facções. Elas trabalham pra Siberian, pra Hering, pra Fórum, pra Zoomp [...] para essas grandes marcas [...] para a Camisaria Colombo [...] então antes a gente tinha um batalhão de reserva [...] essa cidade não suporta mais... deveria ter um projeto para que nenhuma fábrica abra mais no município."
\end{abstract}

As facções, mencionadas pela empresária, atuam como uma espécie de extensão das grandes indústrias. Conforme a FIERN (2014, p. 09): 
As facções costuram peças segmentadas para complementar a linha de produção de indústrias como a Guararapes, Hering e RM-Nor. Empresas com 30 empregados tem faturamento médio de $\mathrm{R} \$ 50$ mil por mês e injetam na economia local $\mathrm{R} \$ 460 \mathrm{mil}$, correspondente a folha de pessoal da atividade de confecção.

Praticamente não há desemprego em São José do Seridó. Observando a cidade, constata-se que durante o período de funcionamento das facções e bonelarias não há movimento de pessoas pelas ruas. Uma cidade que se revela bastante pacata, com casas de alvenaria, ruas pavimentadas, limpas e bem cuidadas. A pergunta seguinte foi elaborada justamente sobre tal temática:

\footnotetext{
(Entrevistador)

"Está desempregado em São José do Seridó quem tem preguiça. Você confirma isso?"

(Empresária)

"É fato vocês visualizarem isso. Depois vocês deem uma volta na cidade, você não vê ninguém fora [...] agora se vocês permanecerem aqui de $11 \mathrm{~h} 00 \mathrm{~min}$ a $11 \mathrm{~h} 30 \mathrm{~min}$ vocês irão ver a rua cheia de gente. Acho que aqui a indústria têxtil emprega mais de 1000 pessoas aqui."
}

De fato, ao se observar a cidade no horário de funcionamento da indústria têxtil, constata-se uma cidade "deserta", com poucas pessoas apenas nas avenidas principais. O censo do IBGE (2010) revela que a taxa de desocupação no município é de 3,96\%. Este indicador leva em consideração empregos formais e não formais.

O município de São José do Seridó, assim, configura-se como um dos principais polos da cadeia têxtil no ramo de vestuário da Região do Seridó, considerando a atuação das facções e da bonelaria. Isso só foi possível, conforme já discutimos anteriormente, graças ao processo de reestruturação produtiva pelo qual passou a região. De janeiro de 2007 a janeiro de 2015, o número de admissões no subsetor de indústria têxtil e vestuário superou o número de demissões (tabela 01), revelando um crescimento deste setor no município de São José do Seridó. Nessa pesquisa, são contabilizados 25 estabelecimentos.

Tabela 01 - Admissões e desligamentos em São José do Seridó no subsetor de indústria e vestuário entre janeiro de

\begin{tabular}{|c|c|c|c|c|c|c|c|}
\hline $\begin{array}{c}\text { Movimentação } \\
\text { agregada }\end{array}$ & Município & \% & Microrregião & \% & UF & \% & Brasil \\
\hline 1) Admissões & 1.186 & 29,05 & 4.082 & 1,97 & 60.178 & 0,03 & 3.851 .220 \\
\hline 2) Desligamentos & 902 & 31,65 & 2.850 & 1,55 & 58.216 & 0,02 & 3.764 .032 \\
\hline $\begin{array}{c}\text { No Emp. Formais - } \\
\mathbf{1 0} \text { Jan/2015 }\end{array}$ & 465 & 23,74 & 1.959 & 1,83 & 25.435 & 0,05 & 1.008 .850 \\
\hline $\begin{array}{c}\text { Total de } \\
\text { Estabelecimentos }\end{array}$ & 25 & 18,25 & 137 & 2,37 & 1.054 & 0,02 & 129.357 \\
\hline
\end{tabular}


O crescimento do setor de bonelaria, o surgimento das facções e a manutenção das fábricas de artefatos têxteis na Região do Seridó são marcas dessa reestruturação, cada dia mais evidente, configurando o território como um espaço no qual a população cria e recria estratégias de sobrevivência para enfrentar tempos difíceis que dificultam ao extremo o desenvolvimento dos municípios e a vida da população.

\section{Conclusões}

De acordo com esta pesquisa, pode-se constatar que a relação de oferta de emprego e a demanda por trabalho no setor de indústria têxtil e de vestuário em São José do Seridó é praticamente nula, uma vez que o setor no município possui todos os seus postos de emprego preenchidos, apesar da sazonalidade na demanda por pedidos de produtos.

Com relação ao processo de reestruturação produtiva e socioespacial pelo qual passou não somente São José do Seridó, mas toda a região seridoense, percebe-se que a presença da indústria têxtil e de vestuário modificou significativamente o território são-josé-seridoense, ressignificando o espaço, pois o município deixou de ser predominantemente rural para ser majoritariamente urbana, fato que é comprovado pelo censo do IBGE no ano de 2010. Por sua vez, a produção dos bens de consumo tem suas matérias-primas oriundas, em sua maioria, da Região do Seridó, mesmo que apresente em seu circuito produtivo insumos de outros estados e regiões do Rio Grande do Norte.

Portanto, compreende-se que a presença das bonelarias e facções em São José do Seridó é de suma importância para o desenvolvimento em escala local/regional, visto que o salário que é pago para os funcionários destas indústrias é gasto tanto no município quanto na própria região, movimentando a economia local/regional, fortalecendo, desse modo, as relações comerciais e a sociedade seridoense.

\section{Referências}

AZEVEDO, Francisco Fransualdo. Reestruturação Produtiva no Rio Grande do Norte. Mercator, Fortaleza, v. 12, n. 2, p.113-132, 30 set. 2013. Mercator - Revista de Geografia da UFC. DOI: 10.4215/rm2013.1202.0008. Disponível

em: <http://www.mercator.ufc.br/index.php/mercator/article/viewArticle/1178>. Acesso em: 01 nov. 2015.

BELTRÃO, Breno Augusto et al (Org.). Projeto cadastro de fontes de abastecimento por água subterrânea estado do rio grande do norte: diagnóstico do município de São José do Seridó Recife: CPRM/PRODEM, 2005. 21 p. Disponível em: < http://www.cprm.gov.br/rehi/atlas/rgnorte/relatorios/SJDS140.PDF>. Acesso em: 13 mar. 2015. 
FIERN - Federação das Indústrias do Rio Grande do Norte (Ed.). Máquinas de costura tecem o desenvolvimento. Revista da Indústria do Rio Grande do Norte, Natal, v. 2, n. 7, p.1-37, jun. 2014. Bimestral. Disponível em: <http://www.fiern.org.br/revista_industria/07/>. Acesso em: 13 mar. 2015.

IBGE. Censo demográfico 2010: São José do Seridó. Disponível em: < http://cod.ibge.gov.br/2Q7 >. Acesso em 13 mar. 2015.

IBGE. Produto interno bruto dos municípios 2012: São José do Seridó. Disponível em: < http://cod.ibge.gov.br/3VZI7>. Acesso em 13 mar. 2015.

IDEMA. Perfil do seu município: São José do Seridó. V.10. Natal, 2008. 24 p. Disponível em: <http://idema.rn.gov.br>. Acesso em: 13 mar. 2015.

MACÊDO, Muirakytan K. de. A Penúltima Versão do Seridó: Uma história do regionalismo seridoense. Natal; Campina Grande: EDUFRN; EDUEPB, 2012. 238 p.

MEDEIROS, Melquides José de Oliveira. Como tudo começou. 2014. Disponível em: <http://www.atstextil.com/\#!hist/c1ktj>. Acesso em: 13 mar. 2015.

MORAIS, I. R. D.; Seridó Norte-Rio-Grandense: uma geografia da resistência. Caicó: Ed. da autora, 2005. 418p.

MORAIS, Ione Rodrigues Diniz. Seridó Norte-Rio-Grandense: Resstruturação e planejamento regional. In: XI ENCONTRO NACIONAL DA ASSOCIAÇÃO NACIONAL DE PÓSGRADUAÇÃO E PESQUISA EM PLANEJAMENTO URBANO E REGIONAL, 11., 2005, Salvador. Anais... . Salvador: Anpur, 2005. p. 1 - 21. Disponível em: <http://unuhospedagem.com.br/revista/rbeur/index.php/anais/article/view/2642/2582>. Acesso em: 01 nov. 2015.

MTE - Ministério do Trabalho e Emprego. Cadastro Geral de Empregados e Desempregados CAGED. Dados e estatísticas: São José do Seridó. Disponível em: < http://bi.mte.gov.br/bgcaged/caged_perfil_municipio/index.php>. Acesso em 14 mar. 2015.

SANTOS, Vaneska Tatiana Silva. Reestruturação socioespacial do Seridó Norte-rio-grandense: desafios e veredas construindo uma "nova" realidade. In: ARAÚJO, Maria Cristina Cavalcanti; SILVA, Valdenildo Pedro da (Org.). Rio Grande do Norte: Temáticas Contemporâneas da Reorganização do Território. Natal: Editora do CEFET-RN, 2007. Cap. 9. p. 220-245. Disponível em: <portal.ifrn.edu.br/pesquisa/editora/livros-para-download/rio.../arquivo>. Acesso em: 1 nov. 2015.

SILVA, Leandro Aparecido da. Arranjos produtivos têxteis e suas relações com a cadeia de suplementos. 2015. 175 f. Dissertação (Mestrado) - Curso de Administração, Universidade Potiguar, Natal, 2015. Disponível em: <https://unp.br/wp-content/uploads/2015/05/ARRANJOSPRODUTIVOS-TÊXTEIS-E-SUAS-RELAÇÕES-COM-A-CADEIA-DE-SUPRIMENTOS.pdf>. Acesso em: 01 nov. 2015. 